\title{
Artes, humanidades e as ciências: música e a mediação de tensões interdisciplinares
}

Ian Cross

Universidade de Cambridge

\section{Pesquisa nas Artes e Humanidades - Contexto histórico}

Nos últimos anos, as justificativas convencionais para valorizar as pesquisas em artes e humanidades - que constrói de forma cumulativa a partir do conhecimento adquirido através da geração de pesquisadores, que amplia nossa compreensão em determinados assuntos e tópicos, e que tal conhecimento e compreensão possuem valor por si - tornam-se cada vez mais difíceis de sustentar em um ambiente acadêmico cada vez mais utilitarista e orientado economicamente. Mesmo o argumento de que tal pesquisa melhora o nosso entendimento sobre nossas histórias, sobre nós mesmos e sobre a condição humana, tem uma repercussão cada vez menor em sociedades ocidentais contemporâneas, cujos governos estão cada vez mais independentes de valores que deram origem a tais argumentos, e que estão voltados a objetivos de curto prazo predominantemente econômicos.

Além disso, a natureza da pesquisa em artes e humanidades tem sido objeto de mudanças cada vez mais rápidas, em parte como consequência de mudanças de valores e em parte como consequência de um aumento de possíveis metodologias. Algumas dessas metodologias surgem e são adotadas como resultado de novos paradigmas intelectuais e compromissos (tal como, por exemplo, a desconstrução). Alguns surgem como disciplinas que redefinem seus objetos de estudo e realinham-se (como no domínio da musicologia, onde as vertentes empírica ou aplicada surgiram da confluência da pesquisa histórica e experimental, ou da nova musicologia, que surgiu a partir da assimilação das 
abordagens etnometodológicas e desconstrucionista do campo da musicologia histórica e cultural). Algumas ainda surgem como consequência da disponibilidade de novas ferramentas de pesquisa; o computador e a internet transformaram as maneiras pelas quais os temas centrais de pesquisa em artes e humanidades podem ser investigados, interpretados e apresentados.

A mudança na natureza e nos valores de pesquisa em artes e humanidades também foi impulsionada por mudanças na natureza do contexto acadêmico mais amplo, onde os mesmos são realizados. Como Clark Kerr assertivamente sugeriu há mais de cinquenta anos em seu livro, The Uses of the University (Os usos da Universidade), as atividades de pesquisas que acontecem nas universidades não podem mais ser entendidas como uma distribuidora de atributos comuns ou motivações, na medida em que propôs a substituição do termo universidade para o termo multiversidade (multiversity). Embora diversos métodos de pesquisa e compromissos ontológicos fizessem parte da universidade moderna no início de sua releitura - em grande parte, no mundo alemão do século XIX - o valor relativo atribuído às várias disciplinas fez com que a universidade contemporânea mudasse radicalmente nos últimos sessenta anos. As oportunidades oferecidas pelo desenvolvimento tecnológico, as relações entre a pesquisa universitária e o mundo comercial, e a crescente pressão para aumentar o número de alunos têm influenciado o valor perceptível de diferentes tipos de pesquisas tanto no âmbito universitário quanto fora dele, nas esferas públicas e governamentais.

Como consequência dessas mudanças e pressões, a natureza da pós-graduação em artes e humanidades teve que se adaptar. Abordagens em textos, fontes, e a história e natureza das ideias serviram como núcleo central para a formação das gerações anteriores de graduandos em artes e humanidades, e a estrutura de um programa de doutorado poderia surgir das exigências dos assuntos abordados. Atualmente, a natureza da formação pós-graduada está delineada por um movimento em direção à homogeneidade da estrutura curricular (incitada pelas agências de fomento), a necessidade em ajustar-se a técnicas, tecnologias e metodologias novas e úteis e justificar o impacto da pesquisa que é realizada. 


\section{Contextos institucionais - sistemas de valores}

Devo discutir essas questões no contexto do sistema do Reino Unido nos dias atuais, no qual todos os financiamentos da universidade vêm do governo, que portanto está na posição de configurar (e constantemente remodelar) as formas nas quais as universidades oferecem oportunidades para a pesquisa e para a formação em pesquisa. Mudanças introduzidas no funcionamento do sistema de financiamento universitário dos últimos vinte anos no Reino Unido estão sendo usados, cada vez mais, na reestruturação dos sistemas universitários financiados pelo Estado em países da Commonwealth (por exemplo, Austrália), e efeitos análogos àqueles causados por mudanças no sistema do Reino Unido parecem estar ocorrendo nos Estados Unidos.

Há cerca de 20 anos, o governo do Reino Unido instruiu a instituição responsável em financiar pesquisas nas universidades do Reino Unido para realizar um exercício de seletividade de pesquisas (research selectivity exercise), classificando pesquisas em cada departamento de cada universidade a fim de fornecer fundos de acordo com a sua colocação. Esta prática tem sido realizada periodicamente, tornando-se cada vez mais prescritiva e exigente no processo. No exercício atual, com o título Research Excellence Framework - Programa de Excelência em Pesquisa (ver http://www.ref.ac.uk/), cada membro da equipe de cada departamento deve apresentar quatro itens publicados entre 2008-2013, cada departamento deve apresentar informações sobre todas as pesquisas e atividades relacionadas à pesquisa (incluindo formação de pós-graduação), receita da pesquisa, meio de pesquisa, e oferecer provas de que a pesquisa realizada no departamento causou impacto fora do mundo acadêmico. Todo este material será então classificado e o financiamento para cada departamento pelos próximos cinco anos dependerá dessa classificação. Existem dificuldades evidentes e desigualdades associadas a este sistema - que vão além da incoerência intelectual que caracteriza a sua operação - que geram tensão entre as instituições (as quais são agora concorrentes) e que privilegiam determinados tipos de pesquisa sobre outras, mas a comunidade acadêmica do Reino Unido teve gradualmente que se adequar a este sistema nas últimas décadas.

As raízes deste sistema de classificação de pesquisa e distribuição de fundos de acordo com a classificação são duas: na aplicação de doutrinas derivadas de estudos de gestão, e na necessidade política pragmática em encontrar um mecanismo para distribuição de fundos (além de evitar a responsabilidade pelas 
consequências da operação deste mecanismo). A partir dos estudos de gestão surge a ideia de indicadores de desempenho que possam ser quantificados, uma abordagem que faz sentido no ambiente de negócios, o qual promete proporcionar um objetivo relacionado ao desempenho e, portanto, um mecanismo de controle de qualidade para identificar o bom e o mau desempenho. A ideia não se adapta bem ao mundo heterogêneo da academia, entretanto, pois não há um objetivo correlato de excelência em pesquisa que pode ser aplicado em todas as disciplinas e métodos de multiversidade. $O$ valor da noção dos indicadores de desempenho para a instituição financeira - o governo - é o que proporciona um meio de distribuição de uma quantia limitada de recursos públicos entre as universidades do Reino Unido. Possibilitou também os governos passados de gerar a ampliação do setor do Ensino Superior no Reino Unido através do aumento de acesso do público a essas instituições, restringindo, assim, despesas.

A conexão da classificação de pesquisa para financiamento no Reino Unido impôs uma série de pressões peculiar - mas provavelmente cada vez mais comum internacionalmente - em pesquisas nas artes e humanidade, pressões que amplificam aquelas que surgiram das dinâmicas da sociedade em geral. $O$ valor econômico pode ser claramente demonstrado em assuntos de ciências e tecnologias $(\mathrm{STEM})^{1}$ (assim como pode o impacto). Portanto, os temas ligados ao STEM, e as formas com as quais estes funcionam em termos de procedimentos de pesquisa envolvendo o trabalho colaborativo, integrado aos programas de formação de pós-graduação, resultados de pesquisas definidos, e, particularmente, potencial para aplicação comercial, passaram a estabelecer padrões pelos quais toda a pesquisa universitária tende a ser julgada.

Como se pode justificar o valor da pesquisa - e a formação para a pesquisa nas artes e humanidades se o ponto de partida - o critério de aceitabilidade - é econômico? As artes e humanidades produzem rendimento que é em grande parte não comercial, mas se pode argumentar que as artes criativas - música, filme, literatura, jogos, dança, artes gráficas e arte conceitual - se constituam em um fator econômico significativo para a economia. Este é sem dúvida o caso; em 2008, o Departamento de Cultura do Reino Unido, Mídia e Esporte

1 STEM é uma sigla indicando ciência, tecnologia, engenharia e matemática, disciplinas consideradas essenciais para a melhoria da competividade e desenvolvimento (Nota editorial). 
informaram que as indústrias criativas empregaram 2 milhões de pessoas na GrãBretanha e contribuíram com 600 bilhões de libras para a economia por ano, $7.3 \%$ do PIB do Reino Unido. É difícil fornecer qualquer evidência coerente para um papel eficaz do setor universitário em direcionar à produção econômica criativa, mas pelo menos os dados possibilitam que as universidades afirmem que as artes criativas têm valor nos termos que são reconhecidos pelo governo. Isto, entretanto, não oferece alívio bastante para as áreas das artes e humanidades que não são classificadas como artes criativas. Distanciando-se de uma agenda que é determinada por exigências de financiamento governamentais e o peso que é, portanto, reconhecido nos processos de pesquisa de todos os tipos encontrados no escopo do STEM, a questão sobre o que pode e deve apoiar a natureza distinta e valor da pesquisa nas artes e humanidades precisa ser abordada.

\section{Ontologias de Pesquisa}

Gostaria de sugerir que, numa primeira abordagem é heuristicamente útil distinguir as pesquisas preocupadas com os estabelecimento ou exploração de causas gerais e teorias daquelas que lidam com o ser humano e o particular. Existem várias estruturas diferentes que podem ajustar e iluminar este tipo de distinção, entre as quais, aquelas propostas por Popper, Bruner e Hacking. Popper sugere:

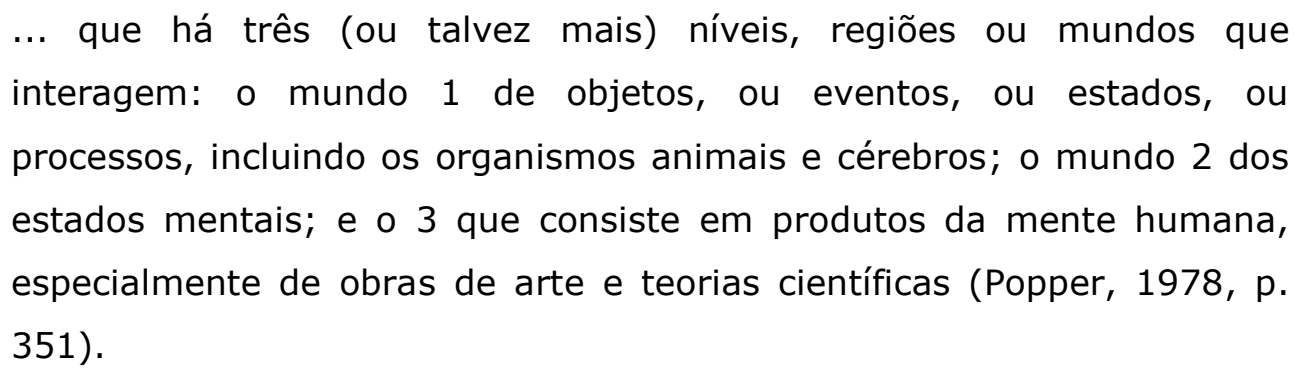

Para Popper, todos os elementos de todos os mundos são susceptíveis a exploração científica e explicação, embora os do mundo 1 possam ser mais susceptíveis do que os do mundo 3.

As distinções de Popper enfatizam como o domínio das ciências se relaciona ao mundo social, e é sobre essa questão que Hacking, em The social Construction of What? (A Construção Social da Realidade) (1999) concentra-se. Hacking faz uma distinção útil entre o que ele classifica em tipos indiferentes e tipos interativos. Os tipos indiferentes são aqueles susceptíveis de ser objeto ou resultado da pesquisa científica, tendo identidades que, apesar de dependentes no modo de 
descoberta e nos relacionamentos de um com o outro, não são afetados pela ação social ou debate. Os tipos interativos são aqueles que surgem em virtude da interação social e do processo cultural. Portanto para Hacking, o genoma humano seria um tipo indiferente, embora claramente suas implicações e usos possam ser interativos. Assim, os tipos indiferentes e interativos de Hacking podem interpenetrar, tipos indiferentes adquirem uma identidade interativa em virtude das formas em se tornam incorporados nas subjetividades dos indivíduos e expressados nas suas interações com outros. Por isso uma distinção clara não pode ser traçada entre estas questões que são abordadas pelas ciências como contrárias às artes e humanidades, mas pelo menos nos limites da dualidade de Hacking - claramente tipos indiferentes, e simplesmente tipos interativos métodos de pesquisa diferenciados devem ser aplicados.

O livro de Bruner de 1986, Actual Minds, Possible Worlds (Realidade Mental, Mundos Possíveis) muda a questão sobre as formas científicas e outras de conhecimento para o domínio mental, propondo uma distinção entre o que ele define como formas de pensamento paradigmático e narrativo. Esta distinção mapeia grosseiramente a separação entre as ciências e métodos humanistas de questionamento e explicação. O pensamento paradigmático, para Bruner:
... lida com questões gerais e, em seu estabelecimento, usa procedimentos para constituir referências verificáveis e testar a verdade empírica [enquanto que o pensamento narrativo] ... lida com o humano ou as intenções humanas, e as vicissitudes e consequências que marcam seus cursos (Bruner 1986, p. 13).

Novamente, esta distinção não é muito clara - particularmente em relação aos aspectos da vida mental do ser humano - mas isto certamente delimita territórios distintos para a pesquisa científica e humanística, talvez mais claramente onde ele sugere que:

... as tentativas da ciência em fazer um mundo que permaneça invariável através das intenções humanas e males humanos... Por outro lado, o humanista lida principalmente com o mundo à medida que ele muda com a posição e postura do espectador (Bruner 1986, p. 50).

É notável que todas as tentativas da filosofia da ciência para demarcar os limites da ciência "apropriada" tenham fracassado quando a pesquisa científica é considerada como uma prática no mundo social. Talvez a tentativa mais bem 
sucedida é a de Lakatos (1970), que propõe que conhecimento científico deve ser considerado como pertencente a teorias principais e auxiliares, com as teorias centrais sendo resistentes à mudança, enquanto as teorias auxiliares são mais passíveis de falsificação. Todavia, mesmo Lakatos não lida satisfatoriamente com a noção, aceita por seu professor Popper, que não existe algo como ciência, somente as ciências; os métodos específicos e compromissos ontológicos de uma ciência podem ser indescritíveis em termos de outra ciência. Assim Lakatos, em última análise, não fornece uma explicação adequada em relação ao que faz as ciências "científicas" e o que impede as abordagens artísticas e humanistas de o serem.

Para concluir esta seção com outra heurística, minha solução favorita para a questão do que constitui as ciências, em vez de outras formas de conhecimento, é sugerir que as ciências tenham métodos e compromissos ontológicos mutuamente comensuráveis (ver Lakoff, 1987, p. 322). Embora os métodos e ontologias de qualquer ciência " $A$ " possam ser compreensíveis à luz de qualquer ciência " $B$ ", é pouco provável que os da ciência " $A$ " sejam capazes de serem expressos em termos de, ou reduzidas para os da ciência "B" (e vice-versa). Assim, pode-se postular uma pluralidade de ciências, mas as teorias, métodos e objetos de cada ciência são mutuamente compreensíveis de maneiras que não se sustentam entre as ciências e outras formas de conhecimentos. Em outras palavras, as ciências são relacionadas umas com as outras, devido suas premissas, métodos de trabalho e teorias poderem ser entendidas pela perspectiva de cada ciência; as premissas, métodos de trabalho e teorias das artes e humanidades parecem, na perspectiva de qualquer ciência, ser de outro tipo.

\section{Epistemologia da pesquisa}

Talvez, em vez de procurar estabelecer uma distinção essencial entre as ciências e as artes \& humanidades, o exame de suas práticas deve lançar luz sobre o que as distinguem. Historicamente, pesquisa em artes e humanidades e pesquisa científica aparentemente envolvem práticas e mecanismos de validação diferentes. Abordagens humanísticas implicam em investigação que atenda explicitamente à autoridade de estudo acadêmico pré-existente, reforçando ou desafiando interpretações com base em novos materiais e novas teorias que prevalecem ou não com base na aceitação de sua validade pela comunidade acadêmica. Pela perspectiva que considera as ciências como práticas sociais, os 
mesmos tipos de procedimentos parecem se aplicar. Entretanto, o papel da autoridade ou validade do conhecimento nas ciências pode ser interpretado como externo ou generalizado pelos processos de revisão por pares, ao passo que a legitimidade do conhecimento nas abordagens humanísticas pode ser vista como mais dependente na reputação, especialização e influência direta.

As artes e humanidades lidam com as particularidades culturais e históricas, interpretando suas evidências para entender a forma como os indivíduos e sociedades fizeram, fazem e refazem seus mundos. Os entendimentos que surgem podem ser vinculados a casos e situações particulares, mas eles podem iluminar essas instâncias de maneiras que irrevogavelmente mudam nossa avaliação deles. Por outro lado, a ciência tem como objetivo estabelecer e explorar causas e teorias gerais. No decurso de realizá-lo, ela simplifica. Em qualquer estudo científico, o que está sendo explorado constitui uma abstração operacional de um domínio do mundo real. A medida em que as conclusões extraídas das manipulações realizadas nessa abstração operacional podem generalizar em relação ao mundo real depende do grau em que a abstração operacional representa adequadamente o domínio do mundo real (ou elementos dele). Os critérios que permitem tais generalizações podem ser especificados em parte para as ciências - especificamente a física, e sua contrapartida tecnológica, a engenharia - que procuram explicar os tipos indiferentes de Hacking. Mas, quando as ciências são aplicadas na exploração de aspectos da experiência humana - quando abordam tópicos que tipicamente representam a preservação da investigação humanística, os tipos interativos de Hacking - os critérios que permitem a generalização para o domínio do mundo real da vida humana a partir das abstrações operacionais em que os métodos científicos se baseiam são cada vez mais difíceis de identificar e aplicar. Apesar dessas dificuldades, a ciência é aplicada para entender a vida social e mental humana, e o problema de avaliar a validade das generalizações que as ciências humanas extraem de seus resultados (um problema que é agudo no estudo científico da música) deve continuamente ser tratado no âmbito da prática científica.

Embora os métodos e as abordagens de pesquisa das ciências e as artes \& humanidades têm uma longa história de diferenças, muitas de suas preocupações e práticas estão sendo reconhecidas como compartilhando características comuns. Nos últimos tempos, o surgimento da internet acelerou a 
convergência das práticas de pesquisas com pesquisadores buscando, cada vez mais, o contexto para suas pesquisas - se documentação ou dados primários, ou estudos anteriormente publicados na web. As formas em que tais fontes (particularmente pesquisas publicadas) são apresentadas e disponíveis são adaptados aos requisitos e exigências das ciências, mas estas ferramentas ainda são frequentemente os únicos meios pelos quais acadêmicos humanistas podem recuperar os materiais em que suas pesquisas dependem. As ferramentas alternativas disponíveis aos acadêmicos humanistas são muito frequentemente, como observa Jensen (2007), direcionadas pelos imperativos comerciais dos gigantes da web como a Google, com, como ele afirma (p. 300) "a autoridade conferida em grande parte por aplauso e popularidade" em vez de reputação e influência.

\section{Centro de Música e Ciência}

O Centro de Música e Ciência (CMS) em Cambridge foi fundado em 2003 em uma ala especialmente construída da Faculdade de Música da Universidade, compreendendo um estúdio com isolamento acústico (com salas de controle e gravação), uma sala de informática, uma de pesquisa, uma sala de máquinas, escritório e espaço para armazenamento. Seu estabelecimento foi possibilitado por ter sido capaz de desenvolver seus pontos fortes existentes, particularmente profissionais já existentes na Faculdade de música em uma nova área de pesquisa (música e ciências), abarcando uma área de pesquisa pouco representada nas universidades do Reino Unido. O Centro foi beneficiado por estar numa instituição com excelente reputação internacional que tem tido, de forma consistente, bom desempenho em avaliações governamentais como as citadas acima, e que tem atraído um alto financiamento do governo para pesquisa. O CMS foi estabelecido a fim de: (i) fornecer instalações para desenvolver experimentos científicos sobre música, (ii) fornecer suporte para pesquisadores da Faculdade de Música trabalhando na área da música \& ciências, particularmente estudantes de pós-graduação, e (iii) fornecer instalações para apoiar colaborações com pesquisadores de outros departamentos da universidade e de outras instituições.

O CMS abriga recursos dedicados à pesquisa intensiva em tecnologia e ao ensino de música que é fundamentalmente colaborativo e interdisciplinar, conectando música à psicologia, fonética, linguística, acústica, ciência da computação e neurociência, assim como outras ciências humanas, tais como antropologia 
biológica e arqueologia. Desde a sua fundação tem atraído uma média anual de oito doutorandos (PhD) e dois ou três mestrandos (MPhil), além de proporcionar uma base colaborativa de pesquisa em doutorado e pós-doutorado com outros departamentos de Cambridge e outras instituições. Projetos colaborativos têm envolvido pesquisadores em Engenharia, Computação, Psicologia e Arqueologia, além de pesquisadores visitantes de instituições dos Estados Unidos, Europa e Austrália. Apesar do carro chefe do Centro ser cognição da música, sua pesquisa é, inerentemente, interdisciplinar, abarcando abordagens ligadas à cognição, computação, psicoacústica, linguística fonética, evolutiva e arqueológica. Conferências e workshops internacionais têm sido organizados, e desde sua fundação em 2003, as pesquisas do CMS têm sido representadas na forma de mais de uma centena de artigos de periódicos revisados por pares e anais de congressos, cerca de trinta capítulos de livro, e três volumes editados (pelas imprensas das Universidade de Cambridge e Universidade de Oxford).

Pesquisas em curso no CMS têm explorado:

- Estruturas e processos cognitivos implicados na experiência do campo musical e ritmo;

- Propriedades que influenciam a experiência da emoção ao ouvir música;

- Influências do movimento corporal e da música nas atitudes e comportamento pró-sociais;

- Processos cognitivos e motores comuns subjacentes à linguagem falada e música;

- O papel da cultura na formação das percepções e cognições musicais;

- Correlatos perceptivos do timbre instrumental;

- Modelos computacionais de processamento musical;

- Arqueologia (reconstrutiva) experimental, explorando a medida em que inferências podem ser obtidas a partir do desgaste relacionado com o uso de pedras "ferramentas" como objetos que produz som ("lito-acústica").

Em paralelo a este estudo experimental, um estudo teórico tem abordado como as tensões entre as abordagens científicas e hermenêuticas servem para entender que a música pode ser compreendida em uma estrutura derivada da teoria evolutiva. Isto tem levado a uma preocupação com a compreensão da 
música como um meio interativo, resultando em estudos experimentais que exploram as formas em que o envolvimento com outras pessoas enquanto produzindo música pode influenciar o desempenho cognitivo e afetivo dos participantes. Deste estudo originou-se uma pesquisa que aborda as similitudes e diferenças entre a música e a linguagem, dando mais atenção às perspectivas biológicas e evolutivas e aos fatores culturais [para maiores informações vide http://cms.mus.cam.ac.uk].

O principal impacto das atividades do Centro pertence necessariamente ao domínio acadêmico, onde o impacto de seu trabalho ultrapassa o domínio dos estudos acadêmicos da música; o significado acadêmico da música tem se destacado, e o domínio da comunicação humana, como uma área importante e consequente para pesquisa dentro de uma série de disciplinas, da arqueologia à antropologia, para a psicologia e linguística. O trabalho do Centro tem sido representado em uma ampla escala de contextos explicitamente preocupados com o envolvimento público à ciência, além de ser amplamente divulgado nos meios de comunicação, incluindo internet, mídia impressa, rádio e televisão.

\section{Pesquisa do CMS - Problemas e Soluções}

As três características chaves da pesquisa e sua formação no CMS são:

1. Interdisciplinaridade

2. Colaboração

3. Estímulo a interesses referentes à pesquisas individuais e originais

Para começar a considerar o papel da interdisciplinaridade: tensões entre concepções humanísticas e científicas, e abordagens para compreender música são resolvidos no dia-a-dia no CMS. Música, parafraseando Alan Merriam (1964), deve ser entendida como som e conceito manifestados no comportamento: música é som, mas para aceitar som como música é necessário que haja um conceito culturalmente determinado e consensual sobre o que se constitui o som musical - e, claro, a produção do som musical requer comportamento. As abordagens humanísticas para música - por exemplo, a perspectiva histórica necessariamente focaliza o domínio conceitual como representado em registros históricos, e no comportamento, contanto que este possa ser inferido a partir desses registros. Em tais abordagens, a música como som, desempenha certo papel em termos das respostas do pesquisador aos sons, bem como suas inferências sobre a função que esses sons tiveram em termos de conceitos e 
comportamentos manifestados no registro histórico. No domínio científico, todos os três níveis - som, conceito e comportamento - devem ser necessariamente levados em conta, portanto todos os níveis definidos por Merriam devem ser reconhecidos e abordados nas pesquisas do CMS. Por exemplo, enquanto o foco aparente em experimentos de psicologia sobre percepção musical está nos comportamentos observáveis de participantes nos experimentos em resposta aos sons musicais preparados pelo pesquisador, o projeto dos experimentos deve considerar os conceitos que são transformados em hipóteses para destacar as maneiras pelas quais um participante possa ouvir os sons musicais, e os objetivos do experimento devem ser elucidar as formas pelas quais estes conceitos se manifestam nos comportamentos dos participantes.

Isso requer dos experimentadores - seja pessoal da equipe ou estudantes de pós-graduação - estar cientes das maneiras em que o som, conceito e comportamento podem ser contextualizados e investigados através dos experimentos. Eles, nós, devemos ser sensíveis na medida em que a estrutura de qualquer experimento em particular - que envolva manipulação de variáveis que constituem abstrações operacionais, a partir do domínio da música do mundo real - reflita adequadamente o problema do mundo real a ser investigado e, por isso, até que ponto as descobertas do experimento possam ser usadas para fazer generalização sobre aquele domínio do mundo real. Esta consciência é estabelecida e mantida por constante interação entre os membros do CMS, no tocante a criticar os experimentos uns dos outros, debatendo sobre métodos e definições, e procurando constantemente esclarecer os termos em que os experimentos são estruturados. Em parte, isso é conseguido através de seminários regulares com membros e estudantes no qual os membros da CMS podem apresentar suas pesquisas uns aos outros ou em que o grupo lê e critica estudos importantes recentes em várias áreas que se enquadram ao âmbito do CMS. É também mantido através das interações informais diárias entre os membros do CMS; os espaços físicos do CMS servem como espaços de estudos, onde todos os membros não somente conduzem suas pesquisas, mas interagem uns com os outros diariamente, sendo que as discussões mais significativas podem muito bem ter acontecido durante o café, em vez de como consequência dos seminários planejados. 
Na realidade, fazer ciência sobre música requer que o cientista seja um músico, um musicólogo e também um cientista. Ele deve se esforçar para alcançar a perspectiva do pesquisador e praticante humanista, de modo a poder avaliar a adequabilidade de qualquer projeto experimental ou descoberta, enquanto mantém o rigor que é exigido para controlar a estrutura e os materiais empregados no experimento, de modo a ser capaz de fazer inferências apropriadas com bases nos padrões estatísticos de seus resultados. A forma paradigmática de Bruner deve ser acoplada ao seu modo narrativo, os tipos indiferentes de Hacking devem poder assumir o papel dos tipos interativos, e a lógica da validação de experimentos deve se resolver em processos de análise, avaliação de projetos experimentais e resultados. Isto exige muito dos estudantes de pós-graduação - contudo, eles estão dispostos a desafios, assim que veem os benefícios de escolher uma visão ampla e integrada de sua disciplina interdisciplinar.

O valor da colaboração no estudo do CMS tem sido destacado e refinado através de colaborações frequentes e heterogêneas com pesquisadores de outras disciplinas, por exemplo, linguística, engenharia, psico-acústica, ciência da computação, ciência dos materiais ou arqueologia. Cada colaborador apresenta diferentes problemas e soluções nas reuniões. Por exemplo, os colaboradores em engenharia sempre apresentam uma abordagem ampla numérica em que o critério de julgamento para o sucesso da pesquisa é baseado na aplicação de métodos quantitativos. Em nossa experiência, os engenheiros têm sido frequentemente relutantes em aceitar lidar adequadamente com a música, que pode implicar na adoção de perspectivas hermenêuticas, mas nossas melhores colaborações - por exemplo, um projeto de três anos explorando os correlatos perceptíveis da acústica do violino, conduzido por membros do CMS, da Faculdade de Engenharia e o Grupo de Percepção Auditiva do Departamento de Psicologia - têm proporcionado, literalmente, uma mudança de mentalidade. Nossos colaboradores de Engenharia referem-se com propriedade em seus trabalhos a conceitos de musicologia, enquanto membros do CMS podem recorrer intuitivamente a conceitos de engenharia. A colaboração, pelo menos como experimentada no CMS, tem proporcionado uma série de experiências recíprocas de aprendizado, enriquecendo e melhorando o rigor do estudo que 
ocorre no Centro, ajudando os pesquisadores de outras disciplinas a valorizarem a investigação humanística.

Em Cambridge temos a vantagem de poder selecionar entre vários candidatos de pós-graduação. Muitos estudantes se inscrevem "somente porque é Cambridge", mas nosso principal critério de admissão é a excelência acadêmica e potencial para desenvolver a pesquisa original. Um critério secundário, mas muito significativo, para admissão à pós-graduação é o candidato apresentar uma personalidade que atenda às exigências e os valores do Centro. O CMS é dirigido por um grupo pequeno e a alta frequência de interações profissionais diárias, juntamente com estresse no trabalho de colaboração requer que os membros do CMS relacionem-se bem intelectual e pessoalmente.

O trabalho do Centro, enquanto amplamente focado nos interesse dos membros da equipe de pesquisa, não é diretivo; nós encorajamos ativamente os membros do CMS, principalmente estudantes de pós-graduação a desenvolver seus interesses originais e individuais de pesquisa. Enquanto os estudantes são obviamente atraídos ao estudo no CMS porque estão interessados em suas áreas de pesquisa existentes, estamos felizes em permitir seus próprios trajetos de pesquisa, a fim de ampliar as linhas de investigação já existentes no Centro, e enfatizar a necessidade dos estudantes em desenvolver seus próprios compromissos intelectuais e direcionamento de pesquisa. Isto contribui para um ambiente de pesquisa estimulante e algumas vezes, competitivo, mas assegura que cada membro doa CMS tenha um senso de liderança e responsabilidade com as atividades do Centro. Algumas vezes, interesses de pesquisa dos estudantes podem levá-los a áreas que estão fora da área de especialização dos membros da equipe; novamente, estamos felizes em possibilitar que isto aconteça desde que tenhamos certeza que orientação especializada possa ser encontrada em outro lugar - com frequência em outros departamentos da Universidade, contribuindo assim para a experiência de aprendizado não somente de nossos alunos como também para nós mesmos, os membros da equipe.

Nós administramos uma vertente de Música \& Ciência em nosso programa de mestrado de um ano na Faculdade, assim como nosso programa de doutorado. Concebemos toda nossa aprendizagem e treinamento como sendo integrados, dos níveis de graduação avançada ao doutorado, com alunos de graduação tendo acesso livre a exames e a participar não somente dos seus próprios seminários, 
mas também das aulas de graduação avançadas, que podem ser proveitosas para eles. Além disso, a Universidade de Cambridge possibilita que os alunos participem de qualquer curso da Universidade, desde que consonante com a logística dos cursos (número de alunos e instalações), e encorajamos nossos pós-graduandos de aproveitar ao máximo o acesso à formação especializada. Estudantes de doutorado também são incentivados a ensinar graduandos em pequenos grupos, o que não somente ajuda no desenvolvimento de suas carreiras como também lhes oferece a oportunidade de aumentar a confiança em suas habilidades em se comunicar de forma eficaz. Além disso, asseguramos que os pós-graduandos concentrem parte de suas energias para divulgar suas próprias descobertas na pesquisa, nas conferências e publicações em revistas.

Finalmente, a divulgação pública se tornou uma vertente significativa das atividades desenvolvidas pela equipe do CMS e pelos alunos. A Faculdade de Música possui um administrador de divulgação dedicado, cuja missão é ampliar o acesso à música e estudo da música em Cambridge através de atividades educativas e artísticas, canalizando as energias da equipe e alunos para performances e apresentações públicas e eventos. Estes podem tomar as mais variadas formas: cursos de música para escolas carentes do Reino Unido; organizando eventos públicos e concertos em ambientes "não-tradicionais", como parques públicos; promover dias abertos (open days), onde o público pode se envolver com as atividades do CMS e aprender sobre abordagens científicas para música, além de poder participar de experiências; na elaboração de shows para crianças em idade escolar de modo a lhes introduzir a novas formas de fazer música e pensar sobre música, que suas escolas podem então desenvolver em suas próprias atividades musicais.

\section{Conclusões}

O CMS existe em um contexto institucional e intelectual particular. Nós nos beneficiamos por sermos incorporados a uma instituição reconhecida internacionalmente e financeiramente estável, que sempre atrai altos níveis de financiamento do governo para pesquisa; sofremos, como todos os departamentos universitários com um foco primário nas artes e humanidades, com as inseguranças que se originam das atitudes governamentais erráticas e, algumas vezes, políticas equivocadas com relação às artes e humanidades. Nosso contexto intelectual gera tensões similares, uma vez que nossa pesquisa e 
formação de pesquisa devem manter um equilíbrio entre riquezas que se originam das pesquisas em música e o rigor e precisão dos pré-requisitos do método científico.

Essas tensões e necessidades de os assuntos concernentes a Artes e Humanidades adaptarem-se a novos panoramas acadêmicos estão sendo cada vez mais reconhecidas no Reino Unido, a nível nacional. Por exemplo, recentemente $\mathrm{o}$ Conselho de Pesquisa em Artes e Humanidades (Arts \& Humanities Research Council), o principal financiador da pesquisa de pósgraduação e pós-doutorado no Reino Unido, introduziu uma nova iniciativa para tentar melhorar o conhecimento de métodos de pesquisa quantitativos típicos das ciências entre os alunos de pós-graduação das artes e humanidades, argumentando que seus métodos são cada vez mais privilegiados na interpretação dos dados acadêmicos, e que alunos de artes e humanidades devem ser incentivados a enfrentar esta mudança. Não estou convencido de que os métodos selecionados seriam particularmente úteis: não se deve coagir estudantes de artes e humanidades a se envolverem em métodos quantitativos se sua relevância para o interesse de pesquisa dos próprios alunos não for evidente. Entretanto, o estudo do CMS sugere uma estratégia alternativa; podese introduzir um componente na formação de doutorado em artes e humanidades que requeira colaboração com um pesquisador da ciência. Este tipo de divulgação interdisciplinar seria benéfico a ambas as partes, e, gostaria de sugerir, essencial para o desenvolvimento de compreensões interdisciplinares. Apesar de todas as pressões institucionais, sociais e intelectuais sobre as artes e humanidades, elas têm muito a ensinar às ciências, assim como as ciências têm a oferecer às Artes e Humanidades. 


\section{References}

BRUNER, Jerome. Actual minds, possible worlds. London: Harvard University Press, 1986.

HACKING, Ian. The social construction of what? London: Harvard University Press, 1999.

JENSEN, Michael. Authority 3.0: friend or foe to scholars? Journal of Scholarly Publishing, n. 39 v.1, p. 297-307, 2007.

KERR, Clark. The uses of the university. London: Harvard University Press, 1963.

LAKATOS, Imre. Falsification and the methodology of scientific research programmes. In: I. Lakatos \& A. Musgrave (Eds.), Criticism and the growth of knowledge. Cambridge: C.U.P., 1970.

LAKOFF, George. Women, fire and dangerous things. Chicago: University of Chicago Press, 1987.

MERRIAM, Alan. P. Purposes of Ethnomusicology, an Anthropological View. Ethnomusicology, n.7, v. 3, p. 206-213, 1963.

POPPER, Karl. Natural selection and the emergence of mind. Dialectica, n. 32, v. 3-4, p. 339-355, 1978. 